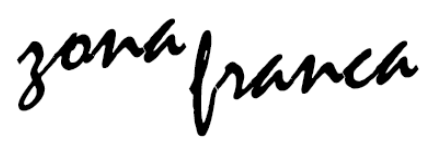

\title{
Experiencias de Profesionales feministas: Red de Psicólogxs Feministas
}

\section{Gisela Cassouto*; Rocío Uceda**}

El 3 de junio del 2015, se dio una masiva movilización contra la violencia hacia las mujeres detrás de la consigna "Ni una menos", que convocó a gran parte de la sociedad argentina a repensarse, y sus efectos se vieron tanto a corto como a largo plazo. Muchas personas que nunca habían problematizado su lugar dentro de una sociedad machista, comenzaron a interpelarlo. Desde ese día como nunca antes se empezaron a tejer los vínculos entre los distintos tipos de violencia machista. Socialmente comenzamos a entender que no hay femicidio sin violencia simbólica, sin un sistema global de opresión del colectivo de varones hacia el colectivo de mujeres y otros géneros.

Sin saberlo aún, ahí comenzó a gestarse lo que luego resultaría en la Red de Psicólogxs Feministas. A partir de ese día y desde lo individual muchxs empezamos a pensar qué podíamos ofrecer desde nuestro rol profesional. Menos de un año después de la primera convocatoria del Ni Una Menos, decidimos juntarnos, salir de lo singular tejiendo redes, hacer causa común y salir de esas situaciones donde a veces nos sentíamos tan solxs. Es por eso que decimos que nosotrxs somos hijxs del Ni Una Menos, ya que sin ese despertar general de la sociedad en lo que a la violencia de género respecta, tal vez nunca nos hubiésemos encontrado.

* Cofundadora y coordinadora de la Red de Psicólogxs Feministas en CABA y GBA. Lic. en Psicología por la Universidad de Buenos Aires. gisela.cassouto@gmail.com

** Miembro de la Red de Psicólogxs Feministas, en Rosario. Psicóloga (UNR), maestranda cohorte 2014 de Maestría Poder y Sociedad desde la Prblemática de GéneroFHyA- UNR. rociouceda@gmail.com 


\section{Primeros pasos}

Éramos varixs Ixs que encontrábamos de frente a la posición clásica de la Psicología: patologización de la diversidad, descreimiento ante el abuso, desconocimiento de las implicancias del patriarcado. Nos pasaba en lo individual y una vez conformadxs como colectivo, con pacientes que relataban el malestar producto del encuentro con otrxs psicólogxs, donde lo que reinaba era el juzgar y normativizar. De esto buscábamos diferenciarnos.

Nos sentíamos solxs, ante la inmensidad de la academia clásica, de las posturas y clasificaciones impartidas como sagradas. Pero decidimos conversar, no ahogarnos. Luego de varias charlas entre colegas, donde manifestábamos estos malestares propios y ajenos, decidimos darle forma a nuestra incomodidad. Optamos por hacer grupo, socializar las posibilidades, y es de allí que surgió la Red de Psicólogxs Feministas.

La creación de la Red de Psicólogxs Feministas es el resultado de darnos cuenta que la problemática se encara en lo colectivo, y que desde nuestra especificidad profesional teníamos algo para ofrecer. Feminismo y Psicología podían ir de la mano y teníamos ganas de hacer esa apuesta.

\section{Apuesta ética}

Quienes trabajamos con Salud Mental, a nuestro parecer, debemos enfrentarnos a las condiciones de un trabajo, que se ubica en y desde lo social. Que Ixs pacientes y usuarios, son parte de una sociedad capitalista y patriarcal, con todos los malestares que ello conlleva, y nosotrxs tampoco estamos por fuera. Cada historia subjetiva se conforma en el entrecruzamiento entre las condiciones sociales, étnicas, religiosas, económicas, etc. que nos configuran. 
Por ello, no abogamos a las representaciones extendidas en ciertas teorizaciones, que apuntan a una individualización, de un sujeto aislado. Apostamos por un trabajo que reflexione las realidades y las posibilidades de transformación de las mismas. Abrirse a una escucha pensada en su complejidad, donde lo social emerge, permite entender que las repitencias y síntomas, están marcadas por el sistema que nos atraviesa y sus consecuencias.

La ideología está presente, siempre. Nuestras ideas sobre el mundo influyen en nuestras escuchas, nuestras lecturas, nuestros diagnósticos. Es con ellas que hacemos nuestro acercamiento hacia aquellos textos que nos formaron. No hay apropiación sin que medie la ideología, ese es un ideal imposible. La teoría se dispone a ser interpelada desde allí, qué lectura hacemos y cómo operamos a partir de ella es, entre otras cosas, una decisión ética.

Como toda práctica social además, la Psicología está atravesada por los ideales, usos y costumbres de la época en la que se enmarca. Es por esto que consideramos que hoy en día desconocer la perspectiva de género como necesaria para nuestra formación y labor profesional es una decisión totalmente política y éticamente errónea. No hay excusas, hay posicionamientos.

\section{Manifiesto feminista}

Somos un grupo de profesionales que creen que es necesario un cambio de perspectiva en el ámbito de la Salud Mental. Consideramos que ésta no abarca únicamente al ámbito individual, sino que trabajamos desde una 
perspectiva integral. Entendemos que existe una relación dialéctica entre lo individual y lo social/cultural. Sostenemos que nuestra sociedad actual está atravesada por imaginarios sociales patriarcales, lo cual tiene distintas implicancias como la exigencia de cumplimiento de mandatos y roles asociados a la identidad impuesta.

Consideramos que muchos de los malestares actuales pueden asociarse a los roles atribuidos según el género asignado al nacer, es decir, a modos específicos de entender la construcción de "lo femenino" y "lo masculino". Estos modos de subjetivación patriarcales cristalizan sentidos y generan sufrimiento psíquico. Nuestro objetivo es generar acciones que tiendan a la equidad entre los géneros y al fin de las violencias patriarcales. Creemos que la práctica psicológica es un factor clave en esta problemática, ya que asistimos todavía a situaciones de maltrato, a partir de la dogmatización de la disciplina psicológica y la no inclusión de una perspectiva de género transversal en la formación de profesionales de la salud mental.

Contribuimos a la lucha de las mujeres a través de diversas acciones desde nuestra especificidad profesional. Éstas van desde asistencia, la orientación y la promoción, hasta la capacitación profesional y el armado de material específico.

Queremos ser una alternativa a la práctica tradicional en Psicología. Nuestra prioridad es garantizar espacios terapéuticos respetuosos y seguros, a partir de un abordaje integral de las subjetividades, y teniendo como horizonte la erradicación de los padecimientos asociados al patriarcado.

\section{Una mirada a futuro}


Creemos que este es el principio, de la Red y de esta nueva oleada feminista de la que formamos parte. Sabemos que el futuro que deseamos no llega solo, sino que es consecuencia de medidas concretas que se tomen en el presente. Es por eso que desde la Red de Psicólogxs Feministas apostamos a la formación constante en materia de diversidad y género, a la obligatoriedad de la perspectiva de género en la formación académica y a interpelar a aquellxs actores sociales que posibilitan o dificultan que en nuestro país esto sea cuestión de Estado. 